\title{
A new bent-toed gecko (Squamata: Gekkonidae: Cyrtodactylus) from the Kimberley region, Western Australia
}

\author{
AARON M. BAUER ${ }^{1 *} \&$ PAUL DOUGHTY ${ }^{2}$ \\ ${ }^{1}$ Department of Biology, Villanova University, 800 Lancaster Avenue, Villanova, Pennsylvania 19085, USA \\ Email: aaron.bauer@villanova.edu \\ ${ }^{2}$ Department of Terrestrial Zoology, Western Australian Museum, 49 Kew St, Welshpool, Western Australia, 6016, Australia \\ *corresponding author
}

\begin{abstract}
A diminutive new species of Cyrtodactylus is described from East Montalivet Island off the north coast of the Kimberley region of Western Australia. Cyrtodactylus kimberleyensis sp. nov. may be distinguished from all other congeners by its small size (gravid female holotype $45 \mathrm{~mm} \mathrm{SVL}$ ), its lack of enlarged subcaudal plates, 16-18 rows of dorsal tubercles, weakly developed ventrolateral skin fold, and dorsal pattern lacking dark transverse bands and enlarged blotches. The new species is one of the smallest in the genus and is the first Cyrtodactylus known from Western Australia. It is not closely related to the large-bodied species of the Cape York Peninsula, Queensland, but rather has affinities to small to mid-sized species occurring on Timor and in the Lesser Sundas, and thus represents a second pathway of colonization of northern Australia.
\end{abstract}

Key words: biogeography, Gekkonidae, Cyrtodactylus kimberleyensis sp. nov., description, taxonomy

\section{Introduction}

Bent-toed geckos of the genus Cyrtodactylus Gray are the most species-rich of all gekkotan genera, with over 140 species and more than half of these have been described in the last decade (Uetz 2011). The greatest rate of new discovery in the group has been in Southeast Asia, particularly Vietnam (e.g., Ziegler et al. 2010; Ngo 2011 and references therein), Thailand (Bauer et al. 2010; Sumontha et al. 2010 and references therein), Malaysia (Chan \& Norhayati 2010; Grismer et al. 2010 and references therein), and Myanmar (Burma) (Bauer 2003; Mahony 2009 and references therein), but more recently new taxa have been recognized from Laos (David et al. 2004; Ngo \& Pauwels 2010; Nguyen et al. 2010; Schneider et al. 2011) and the Philippines (Welton et al. 2009, 2010a, 2010b). From mainland Asia the distribution of Cyrtodactylus extends southeastwards through the islands of Indonesia to New Guinea and thence to north Queensland, Australia and to the Solomon Islands (Rösler et al. 2007). Numerous new taxa have been described from Sulawesi (Hayden et al. 2008; Linkem et al. 2008; Iskandar et al. 2011) and New Guinea (Kraus \& Alison 2006; Kraus 2007, 2008; Rösler et al. 2007; Oliver et al. 2008, 2011), but the recognized diversity of the genus in Australia has remained low.

Following nearly a century of obscurity, Hoplodactylus tuberculatus Lucas \& Frost was transferred to Cyrtodactylus and synonymized with C. louisiadensis (de Vis) by Kluge (1963). Another species based on Australian material, Gymnodactylus olivii Garman was likewise synonymized with C. louisiadensis (Waite 1905) and its provenance questioned. Cyrtodactylus tuberculatus was resurrected by Wells \& Wellington (1984), although no diagnostic features were given to distinguish it from C. louisiadensis. A thorough revision of Australian Cyrtodactylus (Shea et al. 2011) has recognized a total of five members of the genus in Australia, all restricted to portions of northern Queensland. All of the Australian taxa are part of a larger Australo-Papuan clade, which minimally also includes C. novaeguineae (Schlegel), C. zugi (Oliver, Tjaturadi, Mumpuni, Krey \& Richards), C. sermowaiensis (de Rooij), C. loriae (Boulenger), C. salomonensis Rösler, Richards \& Günther, and the members of the C. louisiadensis group (Kraus 2008) or, in other words, all of the members of the genus from east of Wallacea thus far included in a phylogenetic analysis. Most of these species are similar morphologically, with large body size (usually $>100 \mathrm{~mm}$ snout-vent length [SVL]) and a boldly banded dorsal pattern. 
We here describe a small-bodied, non-banded Cyrtodactylus from East Montalivet Island, off the north coast of the Kimberley region of Western Australia (Fig. 1). Despite being considered a 'hotspot' for biodiversity, the Kimberley region is still under-surveyed as revealed by the high rate of species discovery resulting from recent field work (e.g., Köhler 2010; Doughty 2011; Gibson \& McKenzie 2011). One target of recent surveys has been the north-west Kimberley, which has significantly higher rainfall and more rugged terrain than the rest of the region (Storr \& Smith 1975; Smith \& Johnstone, 1981; McKenzie et al. 1991; Gibson \& McKenzie 2011). This area has many endemic species, along with more widely-distributed species favoring tropical savannahs that occur throughout the Kimberley and extend eastwards along to the Northern Territory's Top End region, and to the Gulf country and Wet Tropics of Queensland.

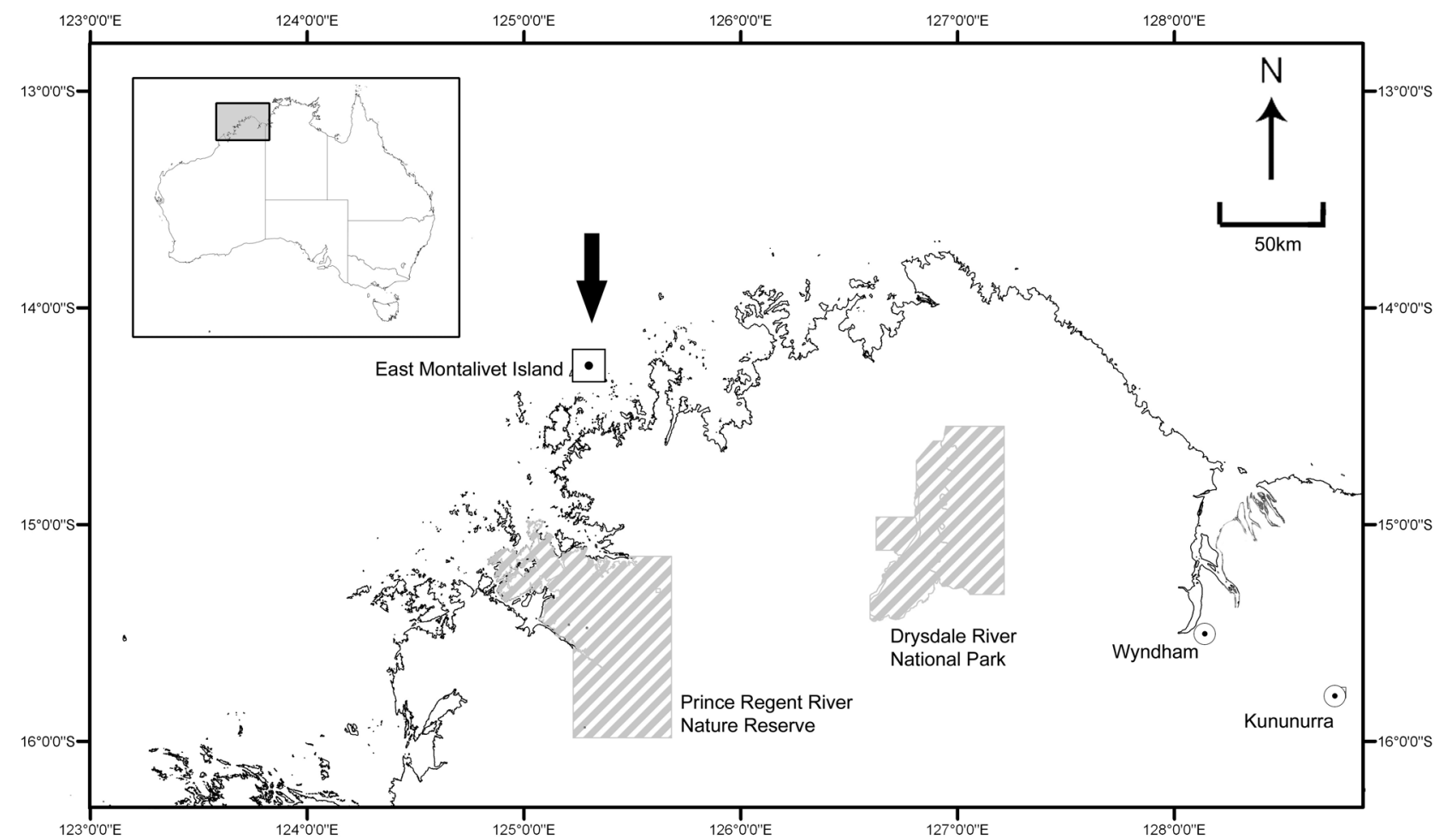

FIGURE 1. Map of the Kimberley region, Western Australia, showing East Montalivet Island (arrow), the type locality of Cyrtodactylus kimberleyensis sp. nov. was collected.

East Montalivet Island is more than $30 \mathrm{~km}$ off the coastline in the extreme north of the Kimberley, making it one of the most isolated islands of the region. The discovery of a Cyrtodactylus from such a location is especially surprising given that no Cyrtodactylus is known from the Kimberley mainland, or indeed from any areas within Australia outside of northern Queensland, on the other side of the continent.

\section{Materials and methods}

The following measurements were taken with digital calipers to the nearest $0.1 \mathrm{~mm}$ following the methods of Bauer (2002, 2003): CrusL: crus length; EarL: ear length; EyeEar: eye to ear distance; ForeaL: forearm length; HeadH: head height; HeadL: head length; HeadW: head width; Internar: internarial distance; Interorb: interorbital distance measured between supraciliary scale rows; NarEye: nares to eye distance; OrbD: orbital diameter; SnEye: snout to eye distance; SVL: snout-vent length; TailL: tail length; TailW: tail width; TrunkL: trunk length. Basal subdigital lamellae were counted from the most proximal lamella at least twice as large as adjacent palmar scales. Measurements and scale counts based on right side of animals unless otherwise noted. Scale counts and external observations of morphology were made using a Nikon SMZ1000 stereo dissecting microscope.

Comparisons were made with museum material in the collections of the California Academy of Sciences, San Francisco (CAS), Museum of Comparative Zoology, Cambridge, Massachusetts (MCZ), and Western Australian 
Museum (WAM; where the holotype is deposited). Original published descriptions and descriptions provided in broader faunal and taxonomic treatments (e.g., Annandale 1913; de Rooij 1917; Darevsky 1964; Auffenberg 1980; Bauer 2002, 2003; Rösler \& Glaw 2008; Linkem et al. 2008) were also consulted.

\section{Cyrtodactylus kimberleyensis sp. nov.}

Kimberley Bent-toed Gecko

Figs. 2-5

Holotype. WAM R164144, gravid adult female (Fig. 2); Australia, Western Australia, Kimberley region, East Montalivet Island $\left(14^{\circ} 16^{\prime} \mathrm{S}, 125^{\circ} 18^{\prime} \mathrm{E}\right)$, collected with a funnel trap in a vine thicket by R. Browne-Cooper, 26 April 2007.

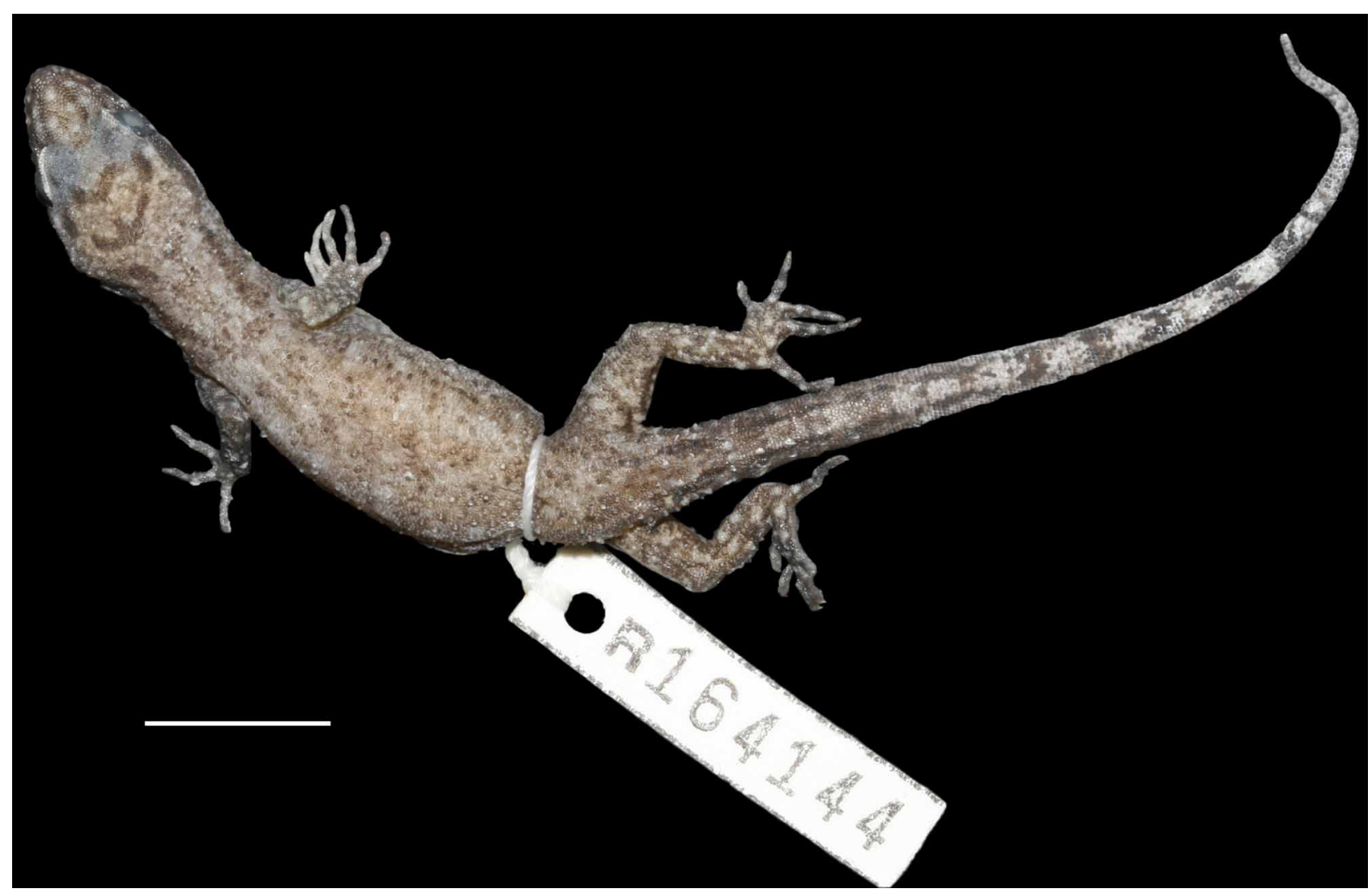

FIGURE 2. Adult female holotype of Cyrtodactylus kimberleyensis sp. nov. (WAM R164144). Scale bar = $10 \mathrm{~mm}$.

Diagnosis. A small sized Cyrtodactylus (female gravid at SVL of $45 \mathrm{~mm}$ ); body slender; limbs and digits relatively long, slender; partly regenerated tail longer than SVL; one pair of greatly enlarged postmental scales in contact with one another behind mental, a smaller pair of enlarged chin shields (second postmentals) lateral to these; small, mostly keeled tubercles in 16-18 longitudinal rows on dorsum; 36 scales across mid-venter between lowest rows of flank tubercles; ventrolateral folds weakly developed and atuberculate; six broad basal lamellae and nine narrow distal lamellae beneath digit IV of pes; dorsal and basal portion of tail only with flattened and keeled tubercles. Color pattern of small diffuse light and dark spots or blotches, no dark transverse bands or large dark blotches.

Description of holotype. Adult female. SVL $45.1 \mathrm{~mm}$; TailL $53.3 \mathrm{~mm}$ (terminal $5.3 \mathrm{~mm}$ regenerated); mass in life $2.5 \mathrm{~g}$. Head moderately long (HeadL/SVL ratio 0.29$)$, narrow $(\mathrm{HeadW} / \mathrm{HeadL}=0.58)$, somewhat depressed $(\mathrm{HeadH} / \mathrm{HeadL}=0.34)$, distinct from neck. Loreal region weakly inflated, canthus rostralis not prominent. Snout elongate ( $\mathrm{SnEye} / \mathrm{HeadL}=0.42)$, somewhat accuminate; longer than eye diameter $(\mathrm{OrbD} / \mathrm{SnEye}=0.58)$; scales on snout small, oval, conical with apex directed posteriorly, mostly homogeneous, distinctly larger than those on crown, interorbital and occipital regions. Eye moderately large $(\mathrm{OrbD} / \mathrm{HeadL}=0.24)$; pupil vertical with crenel- 
ated margins; supraciliaries short, lacking spines or projections. Ear opening horizontally elliptical (right ear opening partly occluded by fold of skin), large $(\mathrm{EarL} / \mathrm{HeadL}=0.10)$; eye to ear distance much greater than diameter of eyes $($ EyeEar/OrbD $=1.42)$. Rostral much wider $(1.9 \mathrm{~mm})$ than deep $(1.0 \mathrm{~mm})$, rostral crease about $2 / 3$ height of rostral. Two slightly enlarged, rhomboidal supranasals separated by a single, smaller, pentagonal internasal. Rostral in contact with first supralabials, nostrils, internasal and supranasals. Nostrils oval, slightly posterolaterallydirected, each surrounded by supranasal, rostral, first supralabial and two postnasals (Fig. 3A). Two to three rows of small scales separate orbit from supralabials. Mental triangular with very acute posteriorly-oriented apex separating anterior $2 / 3$ of postmentals, narrower $(1.8 \mathrm{~mm})$ than deep $(2.2 \mathrm{~mm})$. A single pair of enlarged postmentals in contact behind mental, each bordered anteromedially by mental, anterolaterally by first infralabial, posterolaterally by an enlarged lateral chinshield (or second postmental), and posteriorly by one or two enlarged granules (Fig. 3B). Supralabials to midorbital position 7 (right) to 8 (left); enlarged supralabials to angle of jaws 9 (left) to 10 (right). Infralabials 9 (right) to 10 (left). Interorbital scale rows across narrowest point of frontal bone 11; 33 scales between left and right supraciliary rows.

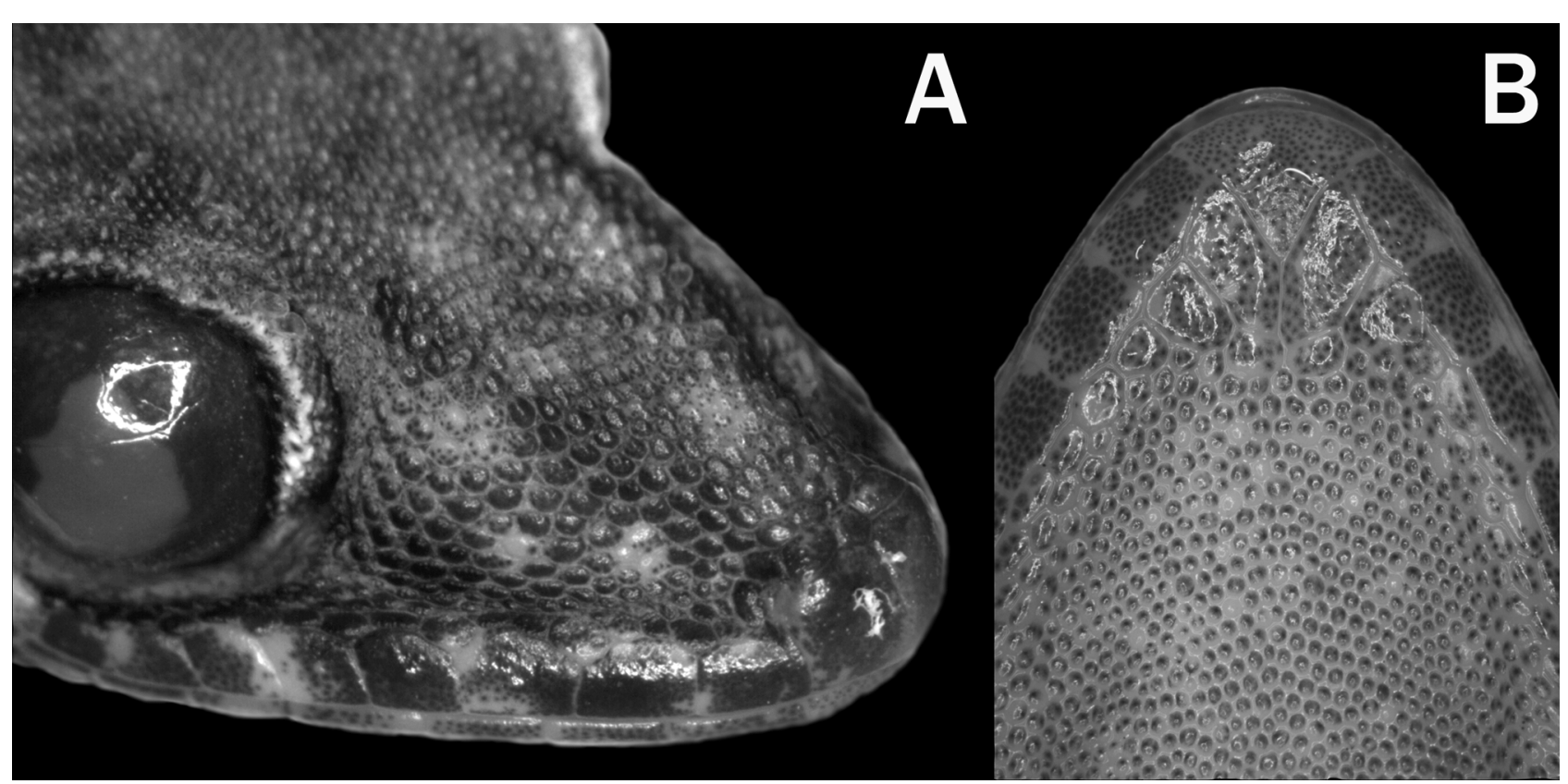

FIGURE 3. Head of Cyrtodactylus kimberleyensis sp. nov. A) oblique view of right side of face showing circumnarial and labial scales; B) ventral view of chin and throat showing mental and post-mental scales.

Body slender, elongate (TrunkL/SVL $=0.42$ ) lacking well defined ventrolateral folds, although small discrete folds clearly present in life. Dorsal scales largely homogeneous, conical with slightly posteriorly-oriented apices; somewhat irregularly distributed tubercles (2-6 times size of adjacent scales), each wider than long, extending from shoulder region on to tail base, smallest on flanks, largest over sacrum, smaller tubercles on postocular region, crown, occiput, and nape; most dorsal tubercles bearing a keel, those on flanks conical, often lacking a distinct keel, those on posterior trunk and sacral region most prominent; tubercles in 16-18 rows at midbody, typically separated from one another by 1-3 dorsal granules (Fig. 2). Ventral scales larger than dorsals, smooth, oval to subtriangular and subimbricate, largest on posterior abdomen and in precloacal region. Midbody scale rows across belly to lowest rows of tubercles $\sim 36$. Gular region with homogeneous, smooth, juxtaposed granular scales.

No precloacal or femoral pores. No precloacal groove. Anteroventral scales of thigh much larger than posteroventral and posterior, but lacking a distinct single row of enlarged femoral scales. Two slightly enlarged, smooth postcloacal spurs, anterior larger than posterior.

Scales on palm and sole smooth, rounded to oval, flattened to slightly domed. Scalation on dorsal surfaces of limbs similar to body dorsum with enlarged, conical, usually keeled tubercles interspersed among smaller scales (except for proximal portion of forearm, which lacks tubercles); tubercles separated from one another by 1-2 small scales, or in direct contact with one another. Fore and hindlimbs moderately short, slender (ForeaL/SVL $=0.12$; 
CrusL/SVL = 0.14). Digits long, slender, inflected at interphalangeal joints, especially antepenultimate joint of longer digits, all bearing robust, slightly recurved claws. Basal subdigital lamellae broad, squarish to rectangular with rounded corners, distalmost generally largest, without scansorial surfaces (1-3-4-5-3 left manus, 1-4-4-5-3 right manus; 2-4-5-6-5 left and right pes); narrow lamellae distal to digital inflection and not including ventral claw sheath: 6-5(tip missing)-8-7-7 (left manus), 6-7-8-8-7 (right manus), 6-7-9-9-9 (left pes), 7-7-9-9-7 (right pes) (Fig. 4 ); very weakly developed interdigital webbing between digits (except IV and V). Relative length of digits: IV $>$ III $>$ II $>$ V $>$ I (manus); V $\sim$ IV $\sim$ III $>$ II $>$ I (pes). Mostly original tail, long, slightly depressed, gently tapering to pointed tip; longer than SVL (TailL/SVL $=1.18)$.

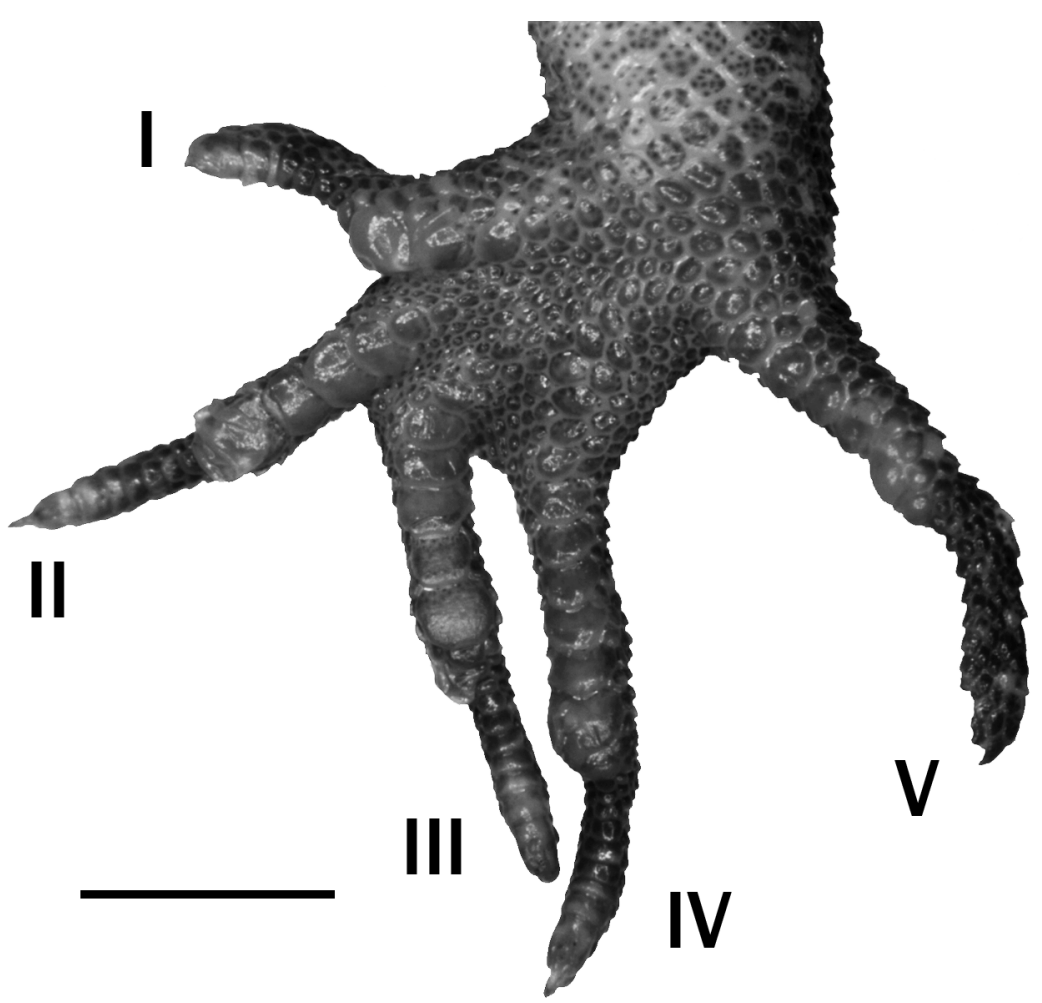

FIGURE 4. Ventral view of right pes of Cyrtodactylus kimberleyensis sp. nov. showing disposition of the subdigital lamellae. Roman numerals indicate digit numbers. Scale bar $=2 \mathrm{~mm}$.

Scales of tail dorsum squarish, flat, juxtaposed to weakly imbricate, arranged in distinct segments of 8-9 scale rows basally, decreasing to 7, then 6 scale rows distally. Pygal segments bearing 6 strongly keeled tubercles, each 5-6 times the size of adjacent scales and separated from each other by 1-2 scales, in a transverse row; next three tail segments with four tubercles, followed by a single segment with two enlarged, flattened, keeled scales in position of tubercles, but on left side only; no tubercles more distally. Subcaudals approximately 1.5 times size of dorsal caudals, squarish proximally, becoming rounded to oval distally. No enlarged median subcaudal plates.

Measurements (in mm): SVL 45.1, ForeaL 5.6, CrusL 6.1, TailL 53.3, TailW 3.5, TrunkL 19.1, HeadL 13.0, HeadW 7.5, HeadH 4.4, OrbD 3.2, EyeEar 4.5, SnEye 5.5, NarEye 3.5, Interorb 4.5, EarL 1.3, Internar 1.2.

Coloration in ethanol: Dorsum light brown mottled with small darker blotches and tubercles. A series of small rounded white blotches on lower flanks, neck and lower part of side of head. Two dark blotches on occiput and a broken, heart-shaped marking on the crown. A broad bold dark brown streak from posterior midpoint of orbit to above ear, confluent with a narrower incomplete stripe continuing on to shoulder. A pair of dark brown canthal streaks and several dark stray marks on other areas of head.

Rostral mostly medium brown. Labials mostly brown with some scales bearing white patches. Limbs similar to dorsum, light brown with darker mottling and distinct white blotches. Digits with alternating light and dark markings. Soles and palms pale grayish brown. Tail light brown with a pair of paravertebral dark brown stripes proxi- 
mally breaking into paired dashes at approximately midpoint of tail. Distal $70 \%$ of tail with alternating white to cream and mid-brown markings. Regenerated tail tip without regular pattern.

Venter beige with cream to whitish spots under throat and posterior border of thighs. Underside of tail uniform brown with white speckling along entire length.

Color in life (based on live photograph of holotytpe, Fig. 5): Similar to that in preservative, pale areas of body with a pale grayish to grayish-pink suffusion, and pale spots on flanks and limbs more evident than in preserved specimen. Pale coloration of tail base pale yellowish-cream to straw. Iris silvery with dark reticulations.

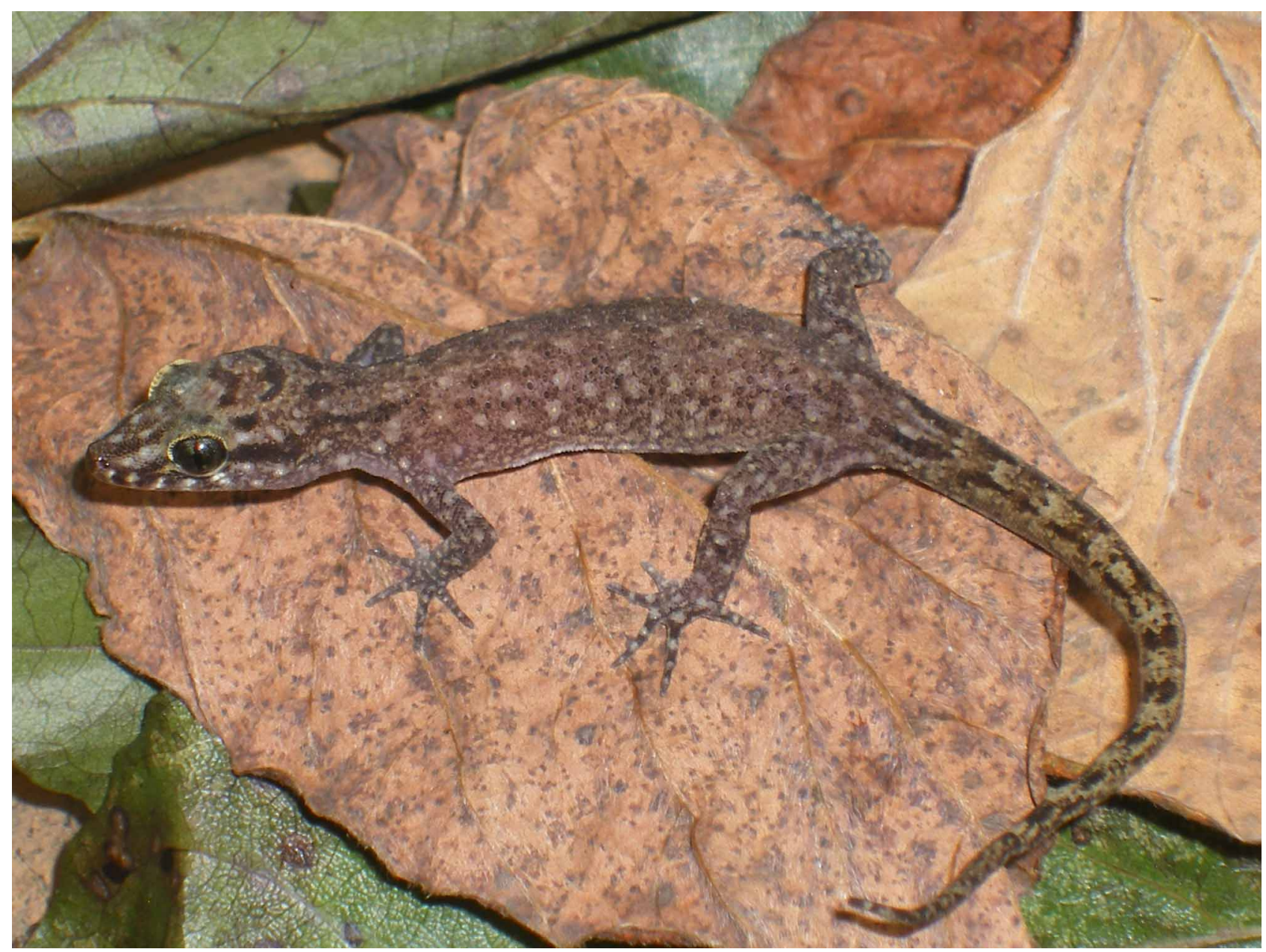

FIGURE 5. Photo in life of the holotype of Cyrtodactylus kimberleyensis sp. nov. (WAM R164144). Photo-R. Browne-Cooper.

Etymology. The specific epithet refers to the Kimberley region of northern Western Australia.

Distribution, reproduction and habitat. The only known specimen of $C$. kimberleyensis sp. nov. is from East Montalivet Island (Fig. 1), although it is possible the taxon occurs on the Kimberley mainland as well. The holotype is a gravid female containing a single egg measuring $9.4 \mathrm{~mm} \times 5.3 \mathrm{~mm}$. Like most gekkotans Cyrtodactylus spp. typically produce two eggs per clutch. Single egg clutches are uncommon in the Gekkonidae (Marquet et al. 1990), but do occur, chiefly in miniaturized lineages. If a single egg clutch is normal for C. kimberleyensis sp. nov. it would be the first member of its genus known to do so. The specimen was collected in late April, very late in the tropical wet season, and it is possible the female had produced other clutches earlier in the season, as occurs in many other tropical geckos (Inger \& Greenberg 1966). The holotype was collected from a vine thicket on a lateritic slope (R. Browne-Cooper, pers. comm.; Fig. 6). Other reptiles also occurring on the island are the gekkotan lizards Heteronotia binoei (Gray) and Delma borea Kluge, the skinks Carlia johnstonei Storr, C. triacantha (Mitchell), Ctenotus inornatus (Gray), Eremiascincus isolepis (Boulenger), Lerista walkeri (Boulenger), and the elapid snake Parasuta nigriceps (Günther). 
Comparisons with other species. The diagnosis of Cyrtodactylus spp. known only from female specimens is generally quite difficult because the presence/absence, number, and distribution of precloacal and femoral pores in males are useful and convenient characters that often distinguish species from one another (Bauer 2003). However, the very small size $C$. kimberleyensis sp. nov. (confirmed as an adult because the sole known specimen is gravid) easily separates it from the majority of its congeners. Most gekkotans show little sexual dimorphism in overall body length, with slightly larger females in approximately two-thirds of species investigated (Fitch 1981). In only two species of Cyrtodactylus are size and maturity data known for large samples (C. malayanus (de Rooij), $\mathrm{n}=131$ males, 162 females; C. pubisulcus Inger, n=56 males, 62 females; Inger \& Greenberg 1966). In both species females were slightly larger on average and attained somewhat greater maximum sizes than males. A review of recent descriptions of new Cyrtodactylus based on samples containing both males and females suggests no intrageneric directionality of sexual dimorphism in SVL, and no clear examples of strong size asymmetry between genders. In $C$. pubisulcus the minimum size at which females were gravid was $89.6 \%$ of maximum SVL and in $C$. malayanus it was $83.1 \%$. (Inger \& Greenberg 1966). Most studies of size at maturity in geckos suggest that females reach maturity at 73-82\% of maximum size (Parker 1972; Vitt 1986; How et al. 1986; Selcer 1986; Okada et al. 2002) although there are some genera in which sexual maturity may be reached at smaller relative sizes (e.g., Ptenopus Gray, Hibbitts et al. 2005; Homonota Gray, Ibargüengoytía \& Casalins 2007). These values may, however, be influenced by the criteria used to determine maturity. For example, in Homopholis wahlbergii Smith females had muscular oviducts at $<50 \%$ of maximum size, but fully developed eggs were only found in females $>71.4 \%$ of maximum size (Whiting et al. 2007).

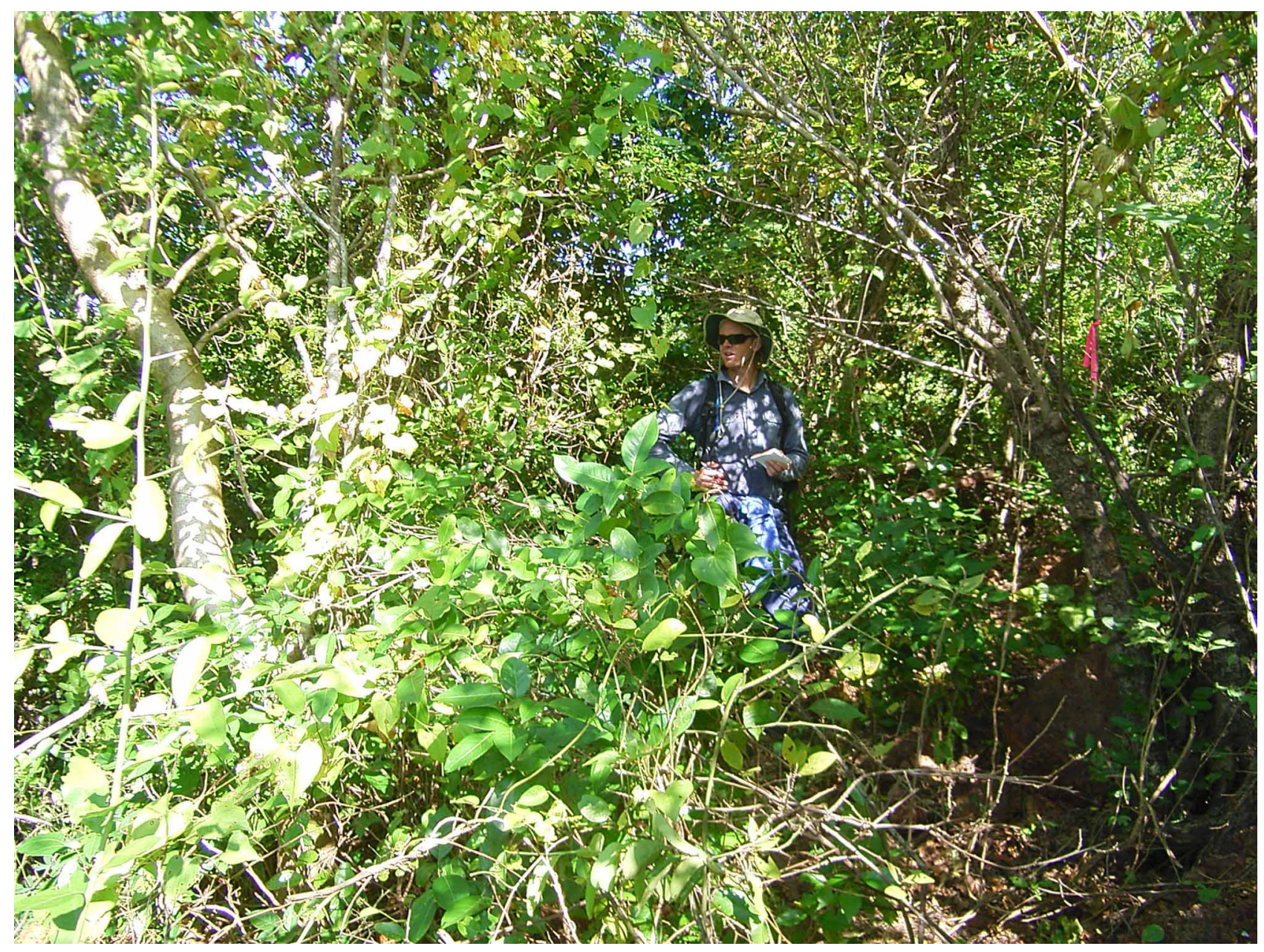

FIGURE 6. Vine thicket habitat of Cyrtodactylus kimberleyensis sp. nov. on East Montalivet Island, Western Australia. Photo -M. Bamford.

Based on data from other geckos one may thus conservatively estimate that the holotype of $C$. kimberleyensis sp. nov. is at least $70 \%$ of the maximum size the species might attain. Of named species summarized by Rösler and 
Glaw (2008), only the following species had maximum SVLs of less than $65 \mathrm{~mm}$, the maximum size of $C$. kimberleyensis sp. nov. so predicted: C. consobrinoides (Annandale), C. feae (Boulenger, C. annandalei Bauer, C. gansi Bauer, and C. wakeorum Bauer-all from Myanmar, C. agamensis (Bleeker) from Sumatra, C. buchardi David et al. from Laos, C. gubernatoris (Annandale) from the eastern Himalayas, C. laevigatus Darevsky from Komodo and Flores, C. malcolmsmithi (Constable) from northern India, and several species in the subgenus Geckoella occurring in peninsular India and Sri Lanka. Cyrtodactylus jellesmae (Boulenger) from Sulawesi was reported to have a maximum SVL of $63 \mathrm{~mm}$ by Rösler \& Glaw (2008) but adults are now known to reach at least $75 \mathrm{~mm}$ SVL (Linkem et al. 2008). All descriptions published since the summary of Rösler and Glaw (2008) were consulted and the only additional taxon with a mature SVL of less than $65 \mathrm{~mm}$ subsequently described is $C$. mandalayensis Mahony. However, this description was based on a single, apparently immature specimen of $61.7 \mathrm{~mm} \mathrm{SVL}$, implying a maximum adult size of >75-85 mm SVL. The new species may be distinguished from Geckoella spp. by its longer toes, more depressed habitus, tail longer than SVL, and tubercular dorsum. By the absence of enlarged caudal midventral plates it may be distinguished from $C$. annandalei and from this species and C. agamensis in having fewer ventral scales across midbody (36 versus 43 and 67, respectively) [Note: The ventral scale count in C. kimberleyensis sp. nov., which lacks ventrolateral folds, was made between the lowest rows of lateral tubercles and is thus not strictly comparable to counts of species with folds. However, as tubercles are never present ventral to such folds, and the ventralmost tubercles are often several scale rows above the folds, the ventral count in the new species may be assumed to be equal to or greater than (but not less than) corresponding inter-fold counts. Inter-fold scale counts of greater magnitude than the inter-tubercle count of the new species may thus be conservatively regarded as putatively diagnostic]. It differs from C. malcolmsmithi in having small caudal tubercles restricted to the proximal portion of the tail (versus prominent tubercles along the entire tail), from C. buchardi, C. annandalei and $C$. consobrinoides, $C$. gansi and $C$. wakeorum in lacking a banded dorsal pattern and from the last two of these, as well as $C$. buchardi, in having a lower number of dorsal tubercle rows (16-18 versus 20-25 [24 in C. wakeorum, 25 in $C$. buchardi]). It is distinguished from C. feae and C. gubernatoris in having a weakly defined ventrolateral fold (versus a well-defined row of enlarged tubercles separating flank and venter) and further from the former species in lacking a reticulate pattern on the head and from the latter in lacking irregular blackish transverse markings on the dorsum. Cyrtodactylus kimberleyensis sp. nov. is the same size as C. laevigatus and C. l. uniformis Auffenberg from Flores but differs from these in its more regularly arranged dorsal tubercles (16-18 discrete longitudinal rows versus scattered or irregularly arranged tubercles) and in having at most a single transverse row of granules separating the proximal and distal series of subdigital lamellae (versus multiple such rows; see Darevsky 1964, Fig. 4; Auffenberg 1980, Fig. 14E). It also differs from these species in dorsal pattern (light and dark blotches versus short, sometimes interrupted transverse bars in the nominate form and mostly patternless in C. l. uniformis).

\section{Discussion}

The very small adult size of Cyrtodactylis kimberleyensis sp. nov. is shared by only a few congeners. Cyrtodactylus buchardi, originally described on the basis of a juvenile of $33.4 \mathrm{~mm} \mathrm{SVL}$, has since been found to reach SVL of $65 \mathrm{~mm}$ (Tenyié \& David, 2010). Indeed, only C. laevigatus from Flores and Komodo is marginally smaller (43 mm SVL; Rösler and Glaw 2008). The new species is also morphologically similar to this species and it is biogeographically intelligible that its closest relatives may be from the Lesser Sundas, which are the nearest possible source areas of bent-toed geckos for the Kimberley. Other species from the Lesser Sundas are also of modest size (C. darmandvillei $75 \mathrm{~mm}$ SVL [86 mm SVL fide Auffenberg 1980], C. wetariensis $70 \mathrm{~mm}$ SVL). All of these species have been recorded from islands of the Inner Banada Arc, including Flores, Komodo, Lombok, Sumbawa, and Wetar. Several undescribed species recently recorded from Timor Leste in the Outer Banda Arc (Kaiser et al. 2011; H. Kaiser pers. comm. 2.xi.2011), and therefore even closer to Western Australia (less than $700 \mathrm{~km}$ ), are also of moderate size and of similar morphology to C. kimberleyensis sp. nov. One of the Timor species is also the most closely related form based on a multigene phylogeny of 64 species of Cyrtodactylus within a clade that includes the Lesser Sunda species (Perry et al. submitted). Members of the Lesser Sunda clade of Cyrtodactylus are morphologically very unlike the five species of the genus that inhabit the Cape York Peninsula of Queensland (Shea et al. 2011) and preliminary phylogenetic results (Perry et al. submitted) suggest that the two groups are deeply divergent and that two independent colonizations of Australia have occurred. 
The discovery of a Cyrtodactylus in the Kimberley was somewhat surprising. The Kimberley harbors many endemic species of reptiles and frogs, and these are almost entirely restricted to the high rainfall zone of the northwest. Many of these endemic northwestern species are associated with rocks and likely have adaptations to the rainfall regime (e.g., Horner 2007; Doughty 2011). Most species from the region, however, are wide-ranging and occur along similar tropical savannah habitats to the east in the Northern Territory and Queensland. Some of the Kimberlely herpetofauna such as frogs of the genera Crinia Tschudi, Uperoleia Gray, and Litoria Tschudi, Green Tree Snakes (Dendrelaphis Boulenger) and Crocodylus Laurenti are shared with these eastern Australian regions as well as with New Guinea and Indonesia. The new species of Cyrtodactylus shows a different pattern, however, as there are no intervening congeners across the Australian monsoonal tropics and its Queensland congeners are only distantly related to it. All evidence suggests that the presence of a Cyrtodactylus in Western Australia is the result of a colonization from the Lesser Sundas. Gekkonid lizards are known for their overwater colonization abilities (Brown \& Alcala 1957; Carranza et al. 2000) and have successfully populated even the most remote oceanic islands, so such a route is plausible.

An intriguing issue is whether C. kimberleyensis sp. nov. occurs on the Australian mainland. A survey of mainland Kimberley rainforest patches, similar to that in which the holotype specimen was collected, found no Cyrtodactylus, although funnel traps and night searching for geckos were not employed (McKenzie et al. 1991). Another possibility is that $C$. kimberleyensis sp. nov. is a true cast-away of a more widely-distributed but previously unrecognized taxon occurring elsewhere, probably in the Outer Banda Arc.

\section{Acknowledgments}

Photos in life and of the habitat courtesy of Robert Browne-Cooper (Eco Logical Australia Pty. Ltd.). The survey on which the new species was collected was funded by INPEX Corporation. We also thank Mike Bamford (Bamford Consulting Ecologists). AMB was supported by grant DEB 0844523 from the National Science Foundation of the United States and PD was supported by a Winston Churchill Trust Fellowship and the Western Australian Museum. The comments of Thomas Ziegler substantially improved the manuscript.

\section{References}

Annandale, N.E. (1913). The Indian geckos of the genus Gymnodactylus. Records of the Indian Museum, 9, 309-326, pls. XVI-XVII.

Auffenberg, W. (1980) The herpetofauna of Komodo, with notes on adjacent areas. Bulletin of the Florida State Museum, Biological Sciences, 25, 39-156.

Bauer, A.M. (2002) Two new species of Cyrtodactylus (Squamata: Gekkonidae) from Myanmar. Proceedings of the California Academy of Sciences, 53, 75-88.

Bauer, A.M. (2003) Descriptions of seven new Cyrtodactylus (Squamata: Gekkonidae) with a key to the species of Myanmar (Burma). Proceedings of the California Academy of Sciences, 54, 463-498.

Bauer, A.M., Kunya, K., Sumontha, M., Niyomwan, P., Pauwels, O.S.G., Chanhome, L. \& Kunya, T. (2010) Cyrtodactylus dumnuii (Squamata: Gekkonidae), a new cave- dwelling gecko from Chiang Mai province, Thailand. Zootaxa, 2570, 4150 .

Brown, W.C. \& Alcala, A.C. (1957) Viability of lizard eggs exposed to sea water. Copeia, 1957, 39-41.

Chan, K.O. \& Norhayati, A. (2010) A new insular species of Cyrtodactylus (Squamata: Gekkonidae) from northeastern Peninsular Malaysia, Malaysia. Zootaxa, 2389, 47-56.

Darevsky, I.S. (1964) Two new species of gekkonid lizards from the Komodo Island in Lesser Sundas Archipelago. Zoologischer Anzeiger, 173, 169-174.

David, P., Nguyen, Q.T., Schneider, N. \& Ziegler, T. (2011) A new species of the genus Cyrtodactylus Gray, 1827 from Central Laos (Squamata: Gekkonidae). Zootaxa, 2833, 29-40.

David, P., Teynié, A. \& Ohler, A. (2004) A new species of Cyrtodactylus Gray, 1827 (Reptilia: Squamata: Gekkonidae) from Southern Laos. Raffles Bulletin of Zoology, 52, 621-627.

de Rooij, N. (1915) The reptiles of the Indo-Australian Archipelago. I. Lacertilia, Chelonia, Emydosauria. E.J. Brill, Leiden, xiv $+384 \mathrm{pp}$.

Doughty, P. (2011) An emerging frog diversity hotspot in the northwest Kimberley of Western Australia: another new frog species from the high rainfall zone. Records of the Western Australian Museum, 26, 209-216.

Fitch, H.S. (1981) Sexual size differences in reptiles. The University of Kansas Museum of Natural History Miscellaneous Pub- 
lication, (70), [4], 1-72.

Gibson, L.A. \& McKenzie, N.L. (2011) Identification of biodiversity assets of selected Kimberley islands: background and implementation. Records of the Western Australian Museum, Supplement, in press.

Grismer, L.L., Shahrul, H., Evan, Q., Mohd, A.M., Chan, K.O., Grismer, J.L. \& Norhayati, A. (2010) A new spiny, prehensiletailed species of Cyrtodactylus (Squamata: Gekkonidae) from Peninsular Malaysia with preliminary hypothesis of relationships based on morphology. Zootaxa, 2625, 40-52.

Hayden, C.J., Brown, R.M., Gillespie, G.M., Setiadi, I., Linkem, C.W., Iskandar, D., Umilaela, T., Bickford, D., Riyanto, P., Mumpuni, A. \& McGuire, J.A. (2008) A new species of bent-toed gecko Cyrtodactylus Gray, 1827 (Squamata: Gekkonidae) from the Island of Sulawesi, Indonesia. Herpetologica, 64, 109-120.

Hibbitts, T.J., Pianka, E.R., Huey, R.B. \& Whiting, M.J. (2005) Ecology of the common barking gecko (Ptenopus garrulus) in southern Africa. Journal of Herpetology, 39, 509-515.

Horner, P. (2007) Systematics of the snake-eyed skinks, Cryptoblepharus Wiegmann (Reptilia: Squamata: Scincidae) — an Australian based review. The Beagle, Supplement, 3, 21-198.

How, R.A., Dell, J. \& Wellington, B.D. (1986) Comparative biology of eight species of Diplodactylus gecko in western Australia. Herpetologica, 42, 471-482.

Ibargüengoytía, N.R. \& Casalins, L.M. (2007) Reproductive biology of the southernmost gecko Homonota darwini: convergent life-history patterns among Southern Hemisphere reptiles living in harsh environments. Journal of Herpetology, 41, 7280.

Inger, R.F. \& Greenberg, B. (1966) Annual reproductive patterns of lizards from a Bornean rainforest. Ecology, 47, $1007-1021$.

Iskandar, D.T., Rachmansah, A. \& Umilaela. (2011) A new bent-toed gecko of the genus Cyrtodactylus Gray, 1827 (Reptilia, Gekkonidae) from Mount Tompotika, eastern peninsula of Sulawesi, Indonesia. Zootaxa, 2838, 65-78.

Kaiser, H., Carvalho, V.L., Ceballos, J., Freed, P., Heacox, S., Lester, B., Richards, S.J., Trainor, C.R., Sanchez, C. \& O’Shea, M. (2011) The herpetofauna of Timor-Leste: a first report. ZooKeys, 109, $19-86$.

Kluge, A.G. (1963) The systematic status of certain Australian and New Guinean gekkonid lizards. Memoirs of the Queensland Museum, 14, 77-85.

Köhler, F. (2010) Uncovering local endemism in the Kimberley, Western Australia: description of new species of the genus Amplirhagada Iredale, 1933 (Pulmonata: Camaenidae). Records of the Australian Museum, 62, 217-284.

Kraus, F. (2007) A new species of Cyrtodactylus (Squamata: Gekkonidae) from western Papua New Guinea. Zootaxa, 1425, $63-68$.

Kraus, F. (2008) Taxonomic partitioning of Cyrtodactylus louisiadensis (Lacertilia: Gekkonidae) from Papua New Guinea. Zootaxa, 1883, 1-27.

Kraus, F. \& Allison, A. (2006) A new species of Cyrtodactylus (Lacertilia: Gekkonidae) from Papua New Guinea. Zootaxa, $1247,59-68$.

Linkem, C.W., McGuire, J.A., Hayden, C.J., Setiadi, M.I., Bickford, D.P. \& Brown, R.M. (2008) A new species of bent-toe gecko (Gekkonidae: Cyrtodactylus) from Sulawesi Island, Eastern Indonesia. Herpetologica, 64, 232-242.

Mahony, S. (2009) Taxonomic status of Cyrtodactylus khasiensis tamaiensis (Smith, 1940) and description of a new species allied to C. chrysopylos Bauer, 2003 from Myanmar (Reptilia: Gekkonidae). Hamadryad, 34, 62-74.

Marquet, P.A., Bozinović, F., Medel, R.G., Werner, Y.L. \& Jaksić, F.M. (1990) Ecology of Garthia gaudichaudi, a gecko endemic to the semiarid region of Chile. Journal of Herpetology, 24, 431-434.

McKenzie, N.L, Johnston, R.B. and Kendrick P.G. (1991). Kimberley rainforests of Australia. Surrey Beatty \& Sons, Chipping Norton, New South Wales, Australia.

Ngo, V.T. (2011) Cyrtodactylus martini, another new karst-dwelling Cyrtodactylus Gray, 1827 (Squamata: Gekkonidae) from Northwestern Vietnam. Zootaxa, 2834, 33-46.

Ngo, V.T. \& Pauwels, O.S.G. (2010) A new cave-dwelling species of Cyrtodactylus Gray, 1827 (Squamata: Gekkonidae) from Khammouane Province, southern Laos. Zootaxa, 2730, 44-56.

Nguyen, Q.T., Kingsada, P., Rösler, H., Auer, M. \& Ziegler, T. (2010) A new species of Cyrtodactylus (Squamata: Gekkonidae) from northern Laos. Zootaxa, 2652, 1-16.

Okada, S., Izawa, M. \& Ota, H. (2002) Growth and Reproduction of Gekko hokouensis (Reptilia: Squamata) on Okinawajima Island of the Ryukyu Archipelago, Japan. Journal of Herpetology, 36, 473-479.

Oliver, P., Krey, K.; Mumpuni; \& Richards, S. (2011) A new species of bent-toed gecko (Cyrtodactylus, Gekkonidae) from the North Papuan Mountains. Zootaxa, 2930, 22-32.

Oliver, P., Tjaturadi, B., Mumpuni, Krey, K. \& Richards, S. (2008) A new species of large Cyrtodactylus (Squamata: Gekkonidae) from Melanesia. Zootaxa, 1894, 59-68.

Parker, W.S. (1972) Aspects of the ecology of a Sonoran Desert population of the western banded gecko, Coleonyx variegatus (Sauria, Eublepharinae). American Midland Naturalist, 88, 209-224.

Rösler, H. \& Glaw, F. (2008) A new species of Cyrtodactylus Gray, 1827 (Squamata: Gekkonidae) from Malaysia including a literature survey of mensural and meristic data in the genus. Zootaxa, 1729, 8-22.

Rösler, H. \& Richards, S.J. \& Günther, R. (2007) Remarks on morphology and taxonomy of geckos of the genus Cyrtodactylus Gray, 1827, occurring east of Wallacea, with descriptions of two new species (Reptilia: Sauria: Gekkonidae). Salamandra, 43, 193-230.

Schneider, N., Nguyen, Q.T., Schmitz, A., Kingsada, P., Auer, M. \& Ziegler, T. (2011) A new species of Karst dwelling Cyrto- 
dactylus (Squamata: Gekkonidae) from Northwestern Laos. Zootaxa, 2930, 1-21.

Selcer, K.W. (1986) Life history of a successful colonizer: the Mediterranean gecko, Hemidactylus turcicus, in southern Texas. Copeia, 1986, 956-962.

Shea, G., Couper, P., Worthington Wilmer, J. \& Amey, A. (2011) Revision of the genus Cyrtodactylus Gray, 1827 (Squamata: Gekkonidae) in Australia. Zootaxa, 3146, 1-63.

Smith, L.A. \& Johnstone, R.E. (1981) Amphibians and reptiles of Mitchell Plateau and adjacent coast and lowlands, Kimberley, Western Australia (pp. 215-227). In: Biological survey of the Mitchell Plateau and Admirality Gulf, Kimberley, Western Australia. Western Australian Museum Press, Perth, Australia.

Storr, G.M. \& Smith, LA. (1975) Amphibians and reptiles of the Prince Regent River Nature Reserve, north-western Australia. In: A biological survey of the Prince Regent River Nature Reserve, north-west Kimberley, Western Australia, in August 1974 (Miles, J.M. \& Burbidge, A.A., eds). Wildlife Research Bulliten of Western Australia, 3, 75-84.

Sumontha, M., Panitvong, N. \& Deein, G. (2010) Cyrtodactylus auribalteatus (Squamata: Gekkonidae), a new cave-dwelling gecko from Phitsanulok Province, Thailand. Zootaxa, 2370, 53-64.

Teynié, A. \& David, P. (2010) Voyages Naturalistes au Laos. Les Reptiles. Editions Revoir, Nohanent. 315 pp.

Uetz, P. (2011). The Reptile Database [http://www.reptile-database.org]. Accessed 8 November 2011.

Vitt, L.J. (1986) Reproductive tactics of sympatric gekkonid lizards with a comment on the evolutionary and ecological consequences of invariant clutch size. Copeia, 1986, 773-786.

Waite, E.R. (1905) An addition to the lacertilian fauna of the Solomon Islands. Records of the Australian Museum, 6, 13-15.

Wells, R.W. \& Wellington, C.R. (1984) A synopsis of the Class Reptilia in Australia. Australian Journal of Herpetology, 1, 73129.

Welton, L.J., Siler, C.D., Diesmos, A.C. \& Brown, R.M. (2009) A new bent-toed gecko (Genus Cyrtodactylus) from southern Palawan Island, Philippines and clarification of the taxonomic status of C. annulatus. Herpetologica, 65, 328-343.

Welton, L.J., Siler, C.D., Diesmos, A.C. \& Brown, R.M. (2010a) Phylogeny-based species delimitation of southern Philippines bent-toes geckos and a new species of Cyrtodactylus (Squamata: Gekkonidae) from western Mindanao and the Sulu Archipelago. Zootaxa, 2390, 49-68.

Welton, L.J., Siler, C.D., Linkem, C.W., Diesmos, A.C. \& Brown, R.M. (2010b) Philippine bent-toed geckos of the Cyrtodactylus agusanensis complex: multilocus phylogeny, morphological diversity, and descriptions of three new species. Herpetological Monographs, 24, 55-85.

Whiting, M.J., Reaney, L.T. \& Keogh, J.S. (2007) Ecology of Wahlberg's velvet gecko, Homopholis wahlbergii, in southern Africa. African Zoology, 42, 38-44.

Ziegler, T., Nazarov, R., Orlov, N., Nguyen, T.Q., Vu, T.N., Dang, K.N., Dinh, T.H. \& Schmitz, A. (2010). A third new Cyrtodactylus (Squamata: Gekkonidae) from Phong Nha-Ke Bang National Park, Truong Son Range, Vietnam. Zootaxa, 2413, 20-36. 